\title{
Plantas tóxicas para ruminantes do Sudoeste de Goiás
}

\author{
Toxic plants for ruminants in Southwestern Goiás, Brazil
}

\author{
Fabiano José Ferreira de Sant’Ana ${ }^{\mathrm{I}^{*}}$ Janildo Ludolf Reis Junior ${ }^{\mathrm{I}}$ Argemiro Pereira Freitas Neto $^{\mathrm{II}}$ \\ Carlos Alberto Moreira Junior ${ }^{\mathrm{II}}$ Valcinir Aloisio Scalla Vulcani ${ }^{\mathrm{II}}$ Rogério Elias Rabelo ${ }^{\mathrm{II}}$ \\ Juliano Pereira Terra ${ }^{\mathrm{IV}}$
}

RESUMO

Com o objetivo de verificar quais são as plantas incriminadas como tóxicas para ruminantes do Sudoeste de Goiás, foram realizadas 108 entrevistas com produtores rurais, médicos veterinários, zootecnistas e agrônomos de 18 municípios da região. Foram apontadas como tóxicas para ruminantes: Brachiaria spp., Enterolobium contortisiliquum, Dimorphandra mollis, Palicourea marcgravii, Pteridium aquilinum e Sorghum vulgare. Adicionalmente, foram informadas intoxicações menos frequentes por Senna occidentalis, Stryphnodendrum obovatum e Manihot esculenta. Casos isolados de intoxicação em bovinos por Asclepias curassavica e Pterodon emarginatus foram descritos por alguns entrevistados. Este trabalho demonstra que intoxicações por plantas tóxicas são frequentes na região avaliada e representam importante causa de prejuízos econômicos aos pecuaristas locais.

Palavras-chave: Centro-Oeste brasileiro, doenças de bovinos, intoxicação por plantas.

\section{ABSTRACT}

The aim of this study was to investigate the toxic plants for ruminants in the Southwestern region of Goiás State, Brazil. 108 people (farmers, veterinarians, zootecnists and agronomists) from 18 counties were interviewed. The following plants were described as toxic for ruminants: Brachiaria spp., Enterolobium contortisiliquum, Dimorphandra mollis, Palicourea marcgravii, Pteridium aquilinum and Sorghum vulgare. In addition, less frequent poisonings by Senna occidentalis, Stryphnodendrum obovatum e Manihot esculenta were reported. Isolated cases of poisoning by Asclepias curassavica and Pterodon emarginatus were described by some interviewers. Based in the results of this research, it is concluded that poisoning by toxic plants are frequent in the studied region and represent important cause of economic losses to the local farmers.

Key words: diseases of cattle, Midwestern Brazil, plant poisoning.

\section{INTRODUÇÃO}

Intoxicações por plantas são responsáveis por prejuízos econômicos significativos na pecuária em várias regiões do mundo. No Brasil, o número de plantas conhecidas como tóxicas para ruminantes e equinos aumentou substancialmente nas últimas décadas. Atualmente, são conhecidas cerca de 130 plantas de interesse pecuário no país (TOKARNIA et al., 2012; PESSOA et al., 2013). Entretanto, apesar do extensivo estudo e vasta literatura relacionada às plantas tóxicas do Brasil (TOKARNIA et al., 1979; RIET-CORREA et al., 1993; RIET-CORREA et al., 2009; TOKARNIA et al., 2012), ainda há carência de informações relacionadas à frequência de intoxicações causadas por plantas em algumas regiões do país (TOKARNIA et al., 2012; PESSOA et al., 2013).

O Estado de Goiás destaca-se no cenário do agronegócio nacional pelos seus elevados índices produtivos, tanto na pecuária de corte, quanto na de leite. Embora algumas pesquisas tenham sido desenvolvidas com bovinos alimentados com Brachiaria spp. no estado (MOREIRA et al., 2009a; MOREIRA et al., 2009b), poucas são as informações disponíveis, até o momento, sobre intoxicações por plantas nas demais espécies herbívoras, particularmente na Região Sudoeste de Goiás. O presente trabalho tem como objetivo fazer

\footnotetext{
'Laboratório de Patologia Veterinária (LPV), Universidade de Brasília (UnB), 70910-900, Brasília, DF, Brasil. E-mail: santanafjf@yahoo.com. *Autor para correspondência.

IIUniversidade Federal de Goiás (UFG), Campus Jataí (CAJ), Jataí, GO, Brasil.

IIICoordenação de Medicina Veterinária, CAJ, UFG, Jataí, GO, Brasil.

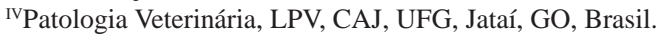


levantamento das principais plantas incriminadas como tóxicas para ruminantes da microrregião Sudoeste do Estado de Goiás.

\section{MATERIAL E MÉTODOS}

A pesquisa foi realizada na microrregião Sudoeste do Estado de Goiás, na qual se situam 18 municípios (Aparecida do Rio Doce, Aporé, Caiapônia, Castelândia, Chapadão do Céu, Doverlândia, Jataí, Maurilândia, Mineiros, Montividiu, Palestina de Goiás, Perolândia, Portelândia, Rio Verde, Santa Helena de Goiás, Santa Rita do Araguaia, Santo Antônio da Barra, Serranópolis) com população de 461.853 habitantes e área de $56.111 \mathrm{~km}^{2}$ (IBGE, 2012). Entre novembro de 2010 e dezembro de 2012, foram realizadas entrevistas com 68 produtores rurais, 33 médicos veterinários, três zootecnistas e quatro agrônomos que trabalham em propriedades rurais da região estudada. Pelo menos, quatro entrevistas por município foram realizadas, totalizando 108 entrevistas. Três questionários adaptados de SILVA et al. (2006) foram empregados nas entrevistas (questionários 1, 2 e 3). Os formulários 1 e 2 foram aplicados a todos os entrevistados e o 3 somente àqueles que se mostraram interessados em descrever surtos de intoxicações por plantas que tenham presenciado. No formulário 1, foram realizadas perguntas sobre as plantas conhecidas como tóxicas na região Centro-Oeste (Brachiaria spp., Enterolobium contortisiliquum, Lantana camara, Palicourea marcgravii, Mascagnia publifora, Vernonia molissima, Vernonia rubricaulis, Cestrum laevigatum, Polygala klotzschii, Senna occidentalis, Dimorphandra mollis, Pteridium aquilinum, Solanum malacoxylon, Stryphnodendrum fissuratum, Stryphnodendrum obovatum, Brachiaria radicans, Manihot esculenta, Sorghum vulgare) (TOKARNIA et al., 2000). A pergunta era formulada mencionando o (s) nome (s) popular (es) e científico da planta e mostrando fotografias da planta ao entrevistado. $\mathrm{O}$ formulário 2 abordou outras plantas conhecidas como tóxicas pelos entrevistados que não foram incluídas no formulário 1 e o formulário 3 incluiu as características epidemiológicas, clínicas e patológicas das intoxicações observadas pelos entrevistados. As plantas relatadas como causadoras de intoxicações, que não estavam no formulário 1, foram coletadas e enviadas ao Herbário Jataiense da Universidade Federal de Goiás (UFG), Campus Jataí (CAJ), para identificação botânica. Adicionalmente, durante o período do estudo, nos casos de intoxicação por plantas em ruminantes que resultaram em morte, necropsias foram realizadas pelos pesquisadores do presente trabalho e várias amostras foram coletadas, fixadas em formol a $10 \%$ e submetidas para exame histopatológico no Laboratório de Patologia Veterinária da UFG/CAJ. Os arquivos desse laboratório foram consultados para coleta dos achados macro e microscópicos desses casos.

\section{RESULTADOS}

Observou-se que onze plantas foram relacionadas com episódios frequentes ou esporádicos de intoxicação em ruminantes na região estudada.

\section{Plantas de toxicidade comprovada}

Brachiaria spp. Cinquenta e nove entrevistados relataram a ocorrência de intoxicação em bovinos, dois em bovinos e ovinos e um exclusivamente em ovinos. Essa intoxicação afetou exclusivamente animais de corte e, em 44 surtos, ocorreu na transição do período chuvoso para o de seca. Em oito surtos, o problema ocorreu exclusivamente na época chuvosa e os sete episódios remanescentes foram descritos apenas na seca da região. Quarenta e três surtos ocorreram em pastagens de $\boldsymbol{B}$. decumbens, nove de $\boldsymbol{B}$. brizantha e dois de $\boldsymbol{B}$. humidicula. Em cinco situações, a intoxicação foi descrita em pastagens que possuíam $\boldsymbol{B}$. decumbens e $\boldsymbol{B}$. brizantha. Surtos de intoxicação em bovinos foram associados às três espécies das plantas mencionadas acima, enquanto que, em ovinos, todos os episódios de toxicose ocorreram em pastos de $\boldsymbol{B}$. decumbens. Em bovinos, a maioria dos surtos foi descrita em bezerros com idade entre 4 e 14 meses (43/59) e 16 casos foram observados em bovinos adultos (21/2 - 7 anos). Todos os ovinos afetados eram jovens (3-5 meses). O principal sinal clínico relatado foi fotossensibilização, também conhecida vulgarmente na região por "requeima" e "sapeca”, e caracterizou-se por dermatite exsudativa e crostosa de evolução subaguda a crônica. As lesões eram mais acentuadas em algumas regiões mais expostas ao sol, como o dorso, orelhas e flancos. Eventualmente, lesões ulcerativas afetavam a parte ventral da língua. Em casos mais graves, foram relatados apatia, prostração e emagrecimento progressivo dos bovinos. Morte de poucos bovinos, associada à intoxicação, foi descrita por seis entrevistados. Já em ovinos, mortalidade ocorreu em todos os surtos. Em geral, os entrevistados mencionaram que os bovinos se recuperam entre 15 e 45 dias após serem retirados das áreas com Brachiaria spp., embora permanecessem com cicatrizes cutâneas das lesões até o momento do abate. Nos casos que foram realizadas necropsias (oito casos), as lesões 
eram restritas à pele e ao fígado. Esse último órgão geralmente estava levemente alaranjado ou amarelado e com padrão lobular evidente. Em alguns casos, o fígado estava levemente firme. Na maioria dos casos, havia acentuada fibrose da cápsula de Glisson. Essa lesão se aprofundava na superfície de corte e possuía cor acinzentada ou esbranquiçada. Em poucos casos, foi observado aumento de volume de linfonodos gastro-hepáticos. Histologicamente, em oito casos, observou-se pericolangite e colangite linfoplasmocítica multifocal leve a moderada, fibrose periportal multifocal moderada a acentuada, proliferação de ductos biliares, degeneração hepatocelular multifocal de intensidade variável, necrose individual aleatória de hepatócitos e infiltração multifocal ou focalmente extensa, acentuada de macrófagos espumosos.

Enterolobium contortisiliquum ("tamboril”, “orelha de macaco"). Trinta e dois entrevistados relataram casos de intoxicação em bovinos, principalmente vacas de corte, que comeram avidamente grande quantidade de favas dessa planta exclusivamente na época da seca, quando havia escassez de forragem nas propriedades. O principal sinal clínico informado foi aborto, especialmente no terço final da gestação, alguns dias após o consumo das favas (23 surtos). Fotossensibilização ocorreu em sete episódios e outras duas vacas morreram após manifestarem diarreia profusa, desidratação, prostração, anorexia e lesões difusas graves de pele. Um produtor do município de Caiapônia informou que, em um ano, 30 vacas de seu rebanho abortaram na mesma época, após o consumo abundante das favas de $\boldsymbol{E}$. contortisiliquum. Em apenas um surto descrito, vacas de leite foram afetadas com manifestação de abortos. Muitos produtores adotaram como medidas de controle da intoxicação o corte das árvores após os episódios.

Dimorphandra mollis ("faveira”). Casos de intoxicação associados ao consumo abundante de favas de $\boldsymbol{D}$. mollis, exclusivamente na época da seca, foram informados por 28 indivíduos. Todos os casos foram observados em vacas de corte criadas extensivamente. A principal manifestação clínica da intoxicação foi aborto no terço final da gestação (26 casos). Algumas dessas vacas manifestaram edema subcutâneo perineal e abdominal, diarreia (eventualmente profusa) com melena, incoordenação, apatia e inapetência. Em dois casos, vacas nãogestantes intoxicadas apresentaram quadro clínico gastrintestinal com edema subcutâneo, similar ao descrito acima, e morte.

Palicourea marcgravii ("cafezinho", “erva de rato”). Oito pessoas descreveram casos muito sugestivos de intoxicação por $\boldsymbol{P}$. marcgarvii em bovinos adultos e jovens. Em todas as situações, 1-3 bovinos de diversas categorias morreram subitamente após serem manejados e estressados. Nas propriedades, havia exemplares da planta com indícios de consumo recente. Os animais caíam, ficavam em decúbito lateral, apresentavam movimentos de pedalagem, opistótono e ingurgitamento da jugular até a morte. Não foi realizada necropsia em nenhum dos surtos.

Pteridium aquilinum ("samambaia”). Onze surtos de intoxicação em bovinos foram relatados pelos entrevistados. Na maioria das propriedades, a planta estava presente em encostas de morros e serras e margens de córregos e rios. Apenas no município de Caiapônia, a planta foi encontrada em grande quantidade nas pastagens. Seis surtos ocorreram nesse município. A maioria dos casos observados foi de intoxicação aguda (10/11), caracterizados clinicamente por melena profusa, hemorragias em mucosas externas e, em um caso, também por hematúria intermitente. Diátese hemorrágica foi observada na necropsia de todos os casos. Apenas um bovino de Caiapônia manifestou intoxicação crônica com hematúria frequente e neoplasmas exuberantes na boca, língua e vesícula urinária. Não foi realizada histopatologia das lesões orais e vesicais desse último caso.

Sorghum vulgare (“sorgo”). Intoxicações por $\boldsymbol{S}$. vulgare utilizado para pastejo foram relatadas por dez entrevistados (nove surtos em bovinos e um em ovinos). A maioria dos produtores menciona que a intoxicação ocorre quando os animais são soltos em áreas de rebrota do sorgo, geralmente entre março e julho. Em todos os casos, cerca de 1-3\% do plantel foi afetado e a maioria dos animais recuperou clinicamente após tratamento com antitóxico e troca de pasto. A letalidade variou de $10-30 \%$. Os sinais clínicos incluíram sialorreia, timpanismo, decúbito esternal e prostração. Em uma propriedade, uma vaca intoxicada abortou.

Senna occidentalis ("fedegoso"). Foram informados cinco surtos de intoxicação por $\boldsymbol{S}$. occidentalis. Em todos os casos, bovinos adultos de corte foram afetados na época da seca. Os animais apresentaram diarreia, inapetência e sinais musculares que consistiam de incoordenação, quedas frequentes, decúbito prolongado e consequente emagrecimento. Em todos os casos, os pastos (alguns degradados) em que os bovinos afetados adoeceram estavam tomados por $\boldsymbol{S}$. occidentalis. Apenas um bovino se recuperou após tratamento com antitóxico e soro glicosado. Nos animais que morreram, o diagnóstico de imunofluorescência direta para raiva foi negativo e não foram detectados fatores epidemiológicos associados com botulismo. Amostras de músculos 
foram avaliadas histologicamente, notando-se degeneração e necrose flocular na musculatura esquelética, principalmente dos membros pélvicos.

Stryphnodendrum obovatum("barbatimão"). Intoxicação por favas dessa planta foi mencionada por sete entrevistados dos municípios de Mineiros e Serranópolis. Todos os casos resultaram em aborto em várias fases da gestação, em bovinos de corte criados extensivamente, sempre na época de seca e com pouca disponibilidade de forragem.

Manihot esculenta ("mandioca”). Foram descritos quatro surtos em bovinos (três bezerros de corte e uma vaca leiteira) e um em ovinos. Em todos os bovinos, os animais morreram minutos após comerem cascas frescas de mandioca recém-colhida; os sinais clínicos consistiram de diarreia, incoordenação, ataxia, timpanismo, cianose de mucosas, dispneia, sialorreia e decúbito lateral. No surto dos ovinos, 25 borregos morreram após comer cascas de mandioca e folhas da planta. O principal sinal clínico descrito foi timpanismo e morte com curso clínico superagudo.

Outras plantas tóxicas mencionadas como tóxicas pelos produtores que não foram incluídas no formulário 1.

Asclepias curassavica ("oficial de sala”, "capitão de sala”). Dois entrevistados descreveram surtos de morte súbita afetando um garrote (por propriedade). Os animais estavam em pastos com grande quantidade da planta. Segundo os proprietários, havia indícios de consumo da planta, mas não foram realizadas necropsias nos bovinos.

Pterodon emarginatus ("sucupira", "sucupira branca”). Em Jataí, foi descrito um surto de intoxicação em bovinos de corte no mês de setembro (final da seca). Aproximadamente, $10 \%$ do plantel adoeceu e dois bovinos morreram. O produtor havia derrubado dez árvores de $\boldsymbol{P}$. emarginatus para obtenção da madeira e deixou folhas e frutos da planta à disposição dos bovinos por um dia. Devido à escassez de forragem na época, os bovinos consumiram avidamente as folhas e frutos da planta. O curso clínico variou de 16-28h. Os sinais clínicos incluíram depressão profunda, retração do flanco, incoordenação e decúbito esternal ou lateral prolongado. Na necropsia de uma vaca intoxicada, notaram-se múltiplas áreas de necrose e hemorragia no fígado. Hemorragias irregulares adicionais também foram observadas no endocárdio, subcutâneo abdominal e serosas do rúmen e do intestino delgado. Histologicamente, notou-se necrose hepatocelular massiva acentuada e hiperplasia de ductos biliares. Bioquímica sérica revelou aumento acentuado da atividade sérica de AST e teores de bilirrubina.

\section{DISCUSSÃO}

Mesmo com todas as limitações existentes e com a dificuldade de comprovar alguns dados relatados pelos entrevistados, as informações geradas por esse trabalho permitiram fazer um levantamento de informações sobre as plantas tóxicas de interesse pecuário para ruminantes da região Sudoeste de Goiás, onde se enfocou a relevância e as características epidemiológicas, clínicas e patológicas das intoxicações relacionadas.

De acordo com os resultados apresentados pelos formulários 1,2 e 3 , é notório que as intoxicações por Brachiaria spp., principalmente pela espécie $\boldsymbol{B}$. decumbens, são as mais frequentes na região. Apesar de a planta ser o principal tipo de forragem presente nos municípios da região Sudoeste de Goiás, casos de intoxicação por essa planta são frequentes e também trazem transtornos econômicos a pecuaristas de toda Região Centro-Oeste (SOUZA et al., 2010; RIET-CORREA et al., 2011; MUSTAFA et al., 2012). Embora essa intoxicação tenha sido descrita em bovinos, ovinos, caprinos e bubalinos, os ovinos são mais susceptíveis que as demais espécies de ruminantes e os ruminantes jovens apresentam maior susceptibilidade à enfermidade (RIETCORREA et al., 2011). Dados muito semelhantes foram observados no presente trabalho. A baixa frequência da intoxicação em ovinos, informada pelos entrevistados, provavelmente está relacionada ao pequeno rebanho desta espécie criado na região. Casos de intoxicação foram relatados em todas as épocas do ano, embora a maioria dos surtos esteja concentrada entre março e junho. Em Mato Grosso do Sul, há sazonalidade semelhante à encontrada na presente investigação, mas a maioria dos casos ocorre em junho e julho (SOUZA et al., 2010). O principal sinal clínico descrito foi fotossensibilização, embora alguns casos com apatia e emagrecimento progressivo adicionais tenham sido informados em bovinos adultos. Características clínicas similares ocorrem em bovinos intoxicados em outras regiões do Brasil (RIET-CORREA et al., 2002; SOUZA et al., 2010).

Outro tipo de intoxicação comum em vacas da região ocorre pelo consumo acentuado de favas de árvores, principalmente de $\boldsymbol{E}$. contortisiliquum e D. mollis, e menos frequentemente de $\boldsymbol{S}$. obovatum, que conduzem a quadro abortivo e entérico. Essas toxicoses foram relatadas em vacas que ingeriram essas favas na época da seca (especialmente entre agosto e setembro), visto que, nesse período, há pouca disponibilidade de forragem em muitas propriedades e coincide com o amadurecimento e consequente queda 
no solo das favas. Em alguns surtos, os entrevistados descreveram os sinais clínicos de fotossensibilização (E. contortisiliquum) e edema subcutâneo (D. mollis). Esse último sinal pode ocorrer após necrose tubular renal aguda na intoxicação por $D$. mollis, conforme observado por outros autores (TOKARNIA \& DÖBEREINER, 1967). Muito produtores da região já conheciam o efeito abortivo dessas plantas e alguns realizam o corte radical ou a introdução de cercas ao redor das árvores para evitar o consumo das favas pelos bovinos. A patogenia dos abortos associados a essa intoxicação é pouco conhecida e, em condições experimentais, a toxicose foi reproduzida em cobaias (BONEL-RAPOSO et al., 2008), mas não foi comprovada em bovinos (TOKARNIA et al., 1999).

E. contortisiliquum tem sido descrita como causa de intoxicação em bovinos no Norte e Nordeste do Brasil, cursando principalmente com diarreia (SILVA et al., 2006; MELLO et al., 2010; SCHONS et al., 2012), fotossensibilização (MELLO et al., 2010; BEZERRA et al., 2012; SCHONS et al., 2012) ou abortos (ASSIS et al., 2009; MELLO et al., 2010; BEZERRA et al., 2012; SCHONS et al., 2012).

Intoxicação por $\boldsymbol{P}$. marcgravii foi informada por alguns dos entrevistados. Embora não tenham sido realizadas necropsias e histopatologia renal nesses casos para confirmação definitiva do diagnóstico, o quadro clínico descrito e a presença da planta com indícios de consumo recente foram muito sugestivas da toxicose. $\boldsymbol{P}$. marcgravii é considerada uma das plantas tóxicas mais importantes do Brasil, em função dos altos índices de mortalidade que provoca e da ampla distribuição pelo território nacional (SCHONS et al., 2012; TOKARNIA et al., 2012; PESSOA et al., 2013). Entretanto, essa planta não tem sido incriminada como causadora de mortalidades em animais em algumas regiões do Nordeste (SILVA et al., 2006; ASSIS et al., 2009; BEZERRA et al., 2012).

Uma intoxicação relativamente frequente na região foi a causada pelo consumo de $\boldsymbol{P}$. aquilinum . Observou-se predominantemente a forma aguda da toxicose com diátese hemorrágica e apenas um caso da forma crônica, com neoplasias na cavidade oral e bexiga. Na região avaliada, a maioria dos municípios possui fazendas com pequena quantidade da planta, geralmente, em beiras de córregos ou encostas de morros, com exceção de Serranópolis, que representou mais da metade dos casos de intoxicação por $\boldsymbol{P}$. aquilinum neste estudo. Nesse município, alguns entrevistados informaram possuírem áreas de pastagem muito invadidas pela planta. Ademais, é possível que esse município possua características favoráveis à planta, como solo ácido. $P$. aquilinum é uma das principais plantas tóxicas da Região Sul do Brasil (GAVA et al., 2002; RISSI et al., 2007; PESSOA et al., 2013).

Intoxicação por plantas cianogênicas, como S. vulgare e M. esculenta, ocorreram com baixa frequência na região estudada, assim como na região Norte do Brasil (SCHONS et al., 2012). No Nordeste do Brasil, essas intoxicações têm sido descritas com maior frequência em bovinos e caprinos (ASSIS et al., 2009; MELLO et al., 2010). No presente trabalho, os surtos ocorreram quando os animais eram colocados em áreas de rebrota de $\boldsymbol{S}$. vulgare ou quando os animais tinham acesso a cascas ou folhas de M. esculenta. Em Rondônia, há casos descritos de intoxicação em bovinos por M. esculenta após consumo de água de lavagem do tubérculo para elaboração de farinha (SCHONS et al., 2012).

Senna occidentalis é uma causa importante de mortalidade de bovinos, principalmente no Sul do Brasil (RISSI et al., 2007; CARMO et al., 2011). No presente trabalho, foram descritos pelos entrevistados poucos episódios de intoxicação. Na região central de Goiás, essa intoxicação já foi observada em javalis criados extensivamente (SANT’ANA et al., 2011).

Das plantas que não estavam no formulário 1 e que foram incriminadas como tóxicas pelos entrevistados, destacam-se Asclepias curassavica e Pterodon emarginatus. Embora tóxica, a primeira é considerada uma planta sem interesse pecuário, pois, devido a sua baixa palatabilidade e à dose tóxica relativamente alta, episódios de intoxicação por essa planta não são comuns (TOKARNIA et al., 2012). P. emarginatus é uma planta que causa necrose hepática aguda em bovinos e que foi recentemente descrita no Centro-Oeste Brasileiro (CRUZ et al., 2012; SANT'ANA et al., 2012). O problema ocorre no final da estação seca, quando há carência de pastagens naturais e quando há queda de árvores após tempestades ou derrubada delas para aproveitamento da madeira. A intoxicação por $\boldsymbol{P}$. emarginatus foi reproduzida em bovinos e ovinos (CRUZ et al., 2012).

Este trabalho demonstra que plantas tóxicas são incriminadas como causa de importantes prejuízos econômicos, inclusive com mortalidade, aos pecuaristas da Região Sudoeste de Goiás. O levantamento dessas informações é útil, não apenas à comunidade científica, mas também aos médicos veterinários que trabalham na região e, primordialmente, aos produtores rurais que, conhecendo as plantas tóxicas e os problemas que elas determinam, obtêm informações úteis no sentido de prevenir futuras intoxicações. 


\section{AGRADECIMENTOS}

Ao Programa de Bolsas de Iniciação Científica do Conselho Nacional de Desenvolvimento Científico e Tecnológico (CNPq) (PIBIC/UFG), à Prof ${ }^{a}$ Luzia Francisca de Souza, do Herbário Jataiense (UFG/CAJ), pela identificação botânica de algumas plantas e a todos os entrevistados que forneceram informações extremamente valiosas para a realização do presente trabalho.

\section{COMITÊ DE ÉTICA E BIOSSEGURANÇA}

O presente trabalho foi aprovado pelo Comitê de Ética em Pesquisa da UFG sob o protocolo 093/10.

\section{REFERÊNCIAS}

ASSIS, T.S. et al. Intoxicações por plantas em ruminantes e equídeos no Sertão Paraibano. Pesquisa Veterinária Brasileira, v.29, n.11, p.919-924, 2009. Disponível em: <http://dx.doi. org/10.1590/S0100-736X2009001100010>. Acesso em: 28 jun. 2013. doi: 10.1590/S0100-736X2009001100010.

BEZERRA, C.W.C. et al. Plantas tóxicas para ruminantes e equídeos da microrregião do Cariri Cearense. Ciência Rural, v.42, n.6, p.1070-1076, 2012. Disponível em: <http://dx.doi. org/10.1590/S0103-84782012000600020>. Acesso em: 27 jun. 2013. doi: 10.1590/S0103-84782012000600020.

BONEL-RAPOSO, J. et al. Intoxicação aguda e abortos em cobaias pelas favas de Enterolobium contortisiliquum (Leg. Mimosoideae). Pesquisa Veterinária Brasileira, v.28, n.12, p.593-596, 2008. Disponível em: <http://dx.doi.org/10.1590/ S0100-736X2008001200005>. Acesso em: 31 jan. 2013. doi: 10.1590/S0100-736X2008001200005.

CARMO, P.M.S. et al. Spontaneous coffe Senna poisoning in cattle: report on 16 outbreaks. Pesquisa Veterinária Brasileira, v.31, n.2, p.139-146, 2011. Disponível em: <http://dx.doi. org/10.1590/S0100-736X2011000200008>. Acesso em: 20 out. 2012. doi: 10.1590/S0100-736X2011000200008.

CRUZ, R.A.S. et al. Intoxicação espontânea e experimental por Pterodon emarginatus (Fabaceae Faboideae) em bovinos e experimental em ovinos. Pesquisa Veterinária Brasileira, v.32, n.11, p.1087-1094, 2012. Disponível em: <http://dx.doi. org/10.1590/S0100-736X2012001100003>. Acesso em: 31 jan. 2013. doi: 10.1590/S0100-736X2012001100003.

GAVA, A. et al. Braken fern (Pteridium aquilinum) poisoning in cattle in southerm Brazil. Veterinary and Human Toxicology, v.44, n.6, p.362-365, 2002.

INSTITUTO BRASILEIRO DE GEOGRAFIA E ESTATÍSTICA. 2012. Disponível em: <www.ibge.gov.br/home>. Acesso em: 07 mar. 2012.

MELLO, G.W.S. et al. Plantas tóxicas para ruminantes e equídeos no Norte Piauiense. Pesquisa Veterinária Brasileira, v.30, n.1, p.1-9, 2010. Disponível em: <http://dx.doi.org/10.1590/S0100736X2010000100001>. Acesso em: 15 dez. 2012. doi: 10.1590/ S0100-736X2010000100001.

MOREIRA, C.N. et al. Bovinos alimentados com Brachiaria e Andropogon: desempenho, avaliação da quantidade de esporos do fungo Pithomyces chartarum e teor de saponinas das pastagens. Ciência Animal Brasileira, v.10, n.1, p.184-194, 2009a. Disponível em: <http://www.revistas.ufg.br/index.php/vet/ article/view/1055>. Acesso em: 28 dez. 2011. doi: 10.5216/cab. v10i1.1055.

MOREIRA, C.N. et al. Bovinos alimentados com Brachiaria spp. e Andropogon gayanus: alterações histológicas de fígado e linfonodos. Ciência Animal Brasileira, v.10, n.1, p.206-218, 2009b. Disponível em: <http://www.revistas.ufg.br/index.php/vet/ article/view/1057>. Acesso em: 28 dez. 2011. doi: 10.5216/cab. v10i1.1057.

MUSTAFA, V.S. et al. Intoxicação natural por Brachiaria spp. em ovinos no Brasil Central. Pesquisa Veterinária Brasileira, v.32, n.12, p.1272-1280, 2012. Disponível em: <http://dx.doi. org/10.1590/S0100-736X2012001200010>. Acesso em: 11 mar. 2013. doi: 10.1590/S0100-736X2012001200010.

PESSOA, C.R.M. et al. Importância econômica, epidemiologia e controle das intoxicações por plantas no Brasil. Pesquisa Veterinária Brasileira, v.33, n.6, p.752-758, 2013. Disponível em: <http://dx.doi.org/10.1590/S0100-736X2013000600011>. Acesso em: 11 mar. 2013. doi: 10.1590/S0100-736X2013000600011.

RIET-CORREA, B. et al. Brachiaria spp. poisoning of ruminants in Brazil. Pesquisa Veterinária Brasileira, v.31, n.3, p.183192, 2011. Disponível em: <http://dx.doi.org/10.1590/S0100736X2011000300001>. Acesso em: 11 mar. 2013. doi: 10.1590/ S0100-736X2011000300001.

RIET-CORREA, F. et al. Intoxicação por plantas e micotoxicoses em animais domésticos. Pelotas: Hemisfério Sul do Brasil, 1993. 340p.

RIET-CORREA, F. et al. Poisoning by plants, mycotoxins and related substances in Brazilian livestock. Santa Maria: Pallotti, 2009. 246p

RIET-CORREA, G. et al. Wasting and death in cattle associated with chronic grazing of Brachiaria decumbens. Veterinary and Human Toxicology, v.44, n.3, p.179-180, 2002.

RISSI, D.R. et al. Intoxicações por plantas e micotoxinas associadas a plantas em bovinos no Rio Grande do Sul: 461 casos. Pesquisa Veterinária Brasileira, v.27, n.7, p.261-268, 2007. Disponível em: <http://dx.doi.org/10.1590/S0100-736X2007000700002>. Acesso em: 9 maio, 2011. doi: 10.1590/S0100-736X2007000700002.

SANT'ANA, F.J.F. et al. Intoxicação espontânea por Senna occidentalis em javalis (Sus scrofa ferus) no Estado de Goiás. Pesquisa Veterinária Brasileira, v.31, n.8, p.702706, 2011. Disponível em: <http://dx.doi.org/10.1590/S0100736X2011000800012>. Acesso em: 27 fev. 2012. doi: 10.1590/ S0100-736X2011000800012.

SANT'ANA, F.J.F. et al. Intoxicação espontânea por Pterodon emarginatus (Fabaceae) em bovinos no Estado de Goiás. Pesquisa Veterinária Brasileira, v.32, n.6, p. 485-489, 2012. Disponível em: <http://dx.doi.org/10.1590/S0100-736X2012000600003>. Acesso em: 27 fev. 2012. doi: 10.1590/S0100-736X2012000600003.

SCHONS, S.V. et al. Intoxicações por plantas em ruminantes e equídeos na região central de Rondônia. Ciência Rural, v.42, n.7, p.1257-1263, 2012. Disponível em: <http://dx.doi.org/10.1590/ S0103-84782012005000047>. Acesso em: 8 fev. 2013. doi:10.1590/S0103-84782012005000047. 
SILVA, D.M. et al. Plantas tóxicas para ruminantes e eqüídeos no Seridó Ocidental e Oriental do Rio Grande do Norte. Pesquisa Veterinária Brasileira, v.26, n.4, p.223-236, 2006. Disponível em: $<$ http://dx.doi.org/10.1590/S0100-736X2006000400007>. Acesso em: 18 fev. 2010. doi: 10.1590/S0100-736X2006000400007.

SOUZA, R.I.C. et al. Intoxicação por Brachiaria spp. em bovinos no Mato Grosso do Sul. Pesquisa Veterinária Brasileira, v.30, n.12, p.1036-1042, 2010. Disponível em: <http://dx.doi. org/10.1590/S0100-736X2010001200006>. Acesso em: $18 \mathrm{fev}$. 2010. doi: 10.1590/S0100-736X2010001200006.

TOKARNIA, C.H.; DÖBEREINER, J. Intoxicação experimental pela fava da faveira (Dimorphandra mollis Benth) em bovinos. Pesquisa Agropecuária Brasileira, v.2, p.367-373, 1967.
TOKARNIA, C.H. et al. Plantas tóxicas da Amazônia a bovinos e outros herbívoros. Manaus: INPA, 1979. 95p.

TOKARNIA, C.H. et al. Experimentos em bovinos com favas de Enterolobium contortisiliquum e Enterolobium timbouva para verificar propriedades fotossensibilizantes e/ou abortivas. Pesquisa Veterinária Brasileira, v.19, n.1, p.39-45, 1999. Disponível em: <http://dx.doi.org/10.1590/S0100-736X1999000100006>. Acesso em: 18 fev. 2010. doi: 10.1590/S0100-736X1999000100006.

TOKARNIA, C.H. et al. Plantas tóxicas do Brasil. Rio de Janeiro: Helianthus, 2000. 320p.

TOKARNIA, C.H. et al. Plantas tóxicas do Brasil para animais de produção. 2.ed. Rio de Janeiro: Helianthus. 2012. 566p. 